\title{
Dynamic Voltage Restorer for Mid Point Compensation using Transformer Less Inverter using Solar PV System
}

\author{
Ezhilarasan G, Mithunraj A, Vishnu Priyan V, Favaz M K
}

\begin{abstract}
The process of electrical phenomenon primarily based Dynamic voltage restoration for a one section of the transmission line voltage dip is presented an unique technique to observe and make amends for the single part where the voltage dips is formed, simulated using advanced simulation techniques. The pre-sag alternative methods are utilized on top of proposed management. Within the aforementioned management technique the proposed where a reference voltage signal is produced matching normal voltage magnitude as well as the frequency Once the proposed restorer is operated with the system, then reference signal's phase will be synchronised with the voltage as this system considers the error if it is a voltage dip. Thus the ability circuit within the voltage restorer produces an amendment of a wave shape to compensate the dip. Circuit components and hence the feedback circuit is discussed.
\end{abstract}

Keywords: Dynamic restoration of voltage, transformer less inverter, swelling in voltage, voltage dip.

\section{INTRODUCTION}

If quality power supply is not ensured to an industry it may result in complete closedown of the industry and may result in losses that are significant to the economical values of a country. Hence the industries invariably demands for prime quality power but however, because of reduced quality cannot be given to the utility. It has been observed conditions which may interfere with the quality of power like, majority of the non-linear in nature loads at various industries may cause transients states that may have an effect on the dependability of the facility provide. Some of the transient conditions in electrical power transmission within the load and hence may disrupt are given as. [1-3].

1. Voltage dips

2. Swelling of Voltages

3. Outages in phases

4. Interruptions in transmission voltages

5. Switching transients caused by capacitor, lighting

6. Loads that is non-linear in nature

7. Line harmonics.

Due to the listed abnormalities, industries have damaged motors, loss of data on in computing systems, error in motion of robotics, increased maintenance as well as increased downtime in plastic based industries, paper rolling plants as

Revised Manuscript Received on December 30, 2019.

G. Ezhilarasan *, Professor, Department of Electrical and Electronic Engineering, AVIT, Chennai, India. Email: ezhilarasan.eee@avit.ac.in

Mithunraj A, Vishnu Priyan V, Favaz M K, UG Students, Department of Electrical and Electronic Engineering, AVIT, Chennai, India, well as semiconductor production units.[4]

The dip in the voltage and swelling of the transient voltage is the worst abnormality when it is frequently occurred. It is also considered as that these abnormalities can last from few fraction of a second to few seconds. Sudden starting of motor, lighting switching, switching compensators in power factor correction units are the major reasons for these conditions [5].

\section{PROPOSED MODELING OF DVR SYSTEM}

\section{A. PV Electrical Structure}

The electrical structure photo voltaic panel is based on the fundamental electric circuit equations of the electrical phenomenon (PV) due to the solar insolation and thermal factors. A photo-cell will delineate by a supply of current as source, which is shunted across by a PN-diode. The working of the solar-PV cell is reverse to the operation of a diode [6] Hence the PV-circuit model has a parallel as well as series resistance (internal) which will delineate by resistors Rs and Rsh, refer fig. 1.

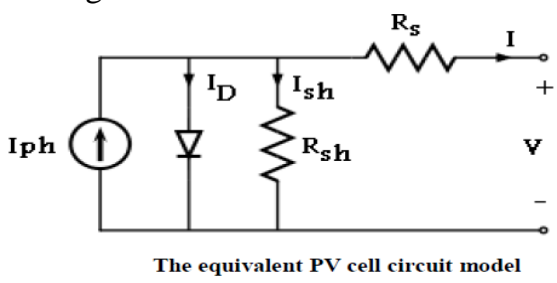

Fig. 1.The equivalent PV cell circuit model

The structure as well as the working of the solar-PV-cell is same as that of a diode and if its PN-junction is exposed to sun will produce the reverse effect of that of a diode. The equations below shall be referred.

$\mathrm{I}=\mathrm{I}_{\mathrm{ph}, \text { cell }}-\mathrm{I}_{\mathrm{D}}$

$I_{D}=I_{o, \text { cell }} * \exp \left[\left(\frac{q V}{A K T r}\right)-1\right]$

Eq. 1,2 is re-framed to get the voltage as well as the current characteristics of a PV-Cell of a bigger solarcell arrangement in panel just including few parameters referred in Eq. 3,4,5

$$
\begin{aligned}
& \mathrm{I}=\mathrm{Iph}-\mathrm{Io} * \exp [((\mathrm{q}(\mathrm{v}+\mathrm{IRs})) / \mathrm{AKTc})-1]-[(\mathrm{V}+\mathrm{IRs}) / \mathrm{Rsh}] \\
& \mathrm{V}=\mathrm{AKTc} / \mathrm{q} \ln [(\mathrm{Iph}-\mathrm{Io}-\mathrm{I}) / \mathrm{Io}]-\mathrm{IRs} \\
& \mathrm{I}=\mathrm{Iph}-\mathrm{Io} * \exp [(((\mathrm{v}+\mathrm{IRs})) / \mathrm{AKTc})-1] \\
& \mathrm{Vt}=\mathrm{NsKTc} / \mathrm{q}
\end{aligned}
$$

Here K,Tc shall have similar thermal unit, namely Kelvin. Also the factor ' $\mathrm{A}$ ' in curve fitting shall adjust to static characteristics of the PV-cell. 
From (3) and (4) the voltage corresponding to one PV-Cell used to multiply all the PV-Cells in series connection to obtain the voltage rating of the array also the current as it in the addition of the current that goes thro the PV-cells in their parallel circuits, the I is obtained by dividing the current in the array using the no. of cells shunted across eq. (4), gives a valid PV-cell operating thermal temperature given as Tc and its insolation level[7]

For any change in the levels of temperature or solar insolation, the PV array voltage as well as the current will follow this change. So for the changes in temperature or insolation, shall be included while modeling the PV-cell as a model array. The methodology of this modeling is depicted explicitly by the author Buresch in his technical article.[8] with the known thermal conditions and insolation levels, an accurate PV model can be obtained to demonstrate different thermal as well as insolation levels. Now this can be made as a reference thermal temperature (Tc) for a known insolation level $(\mathrm{G})$ as per the specification.

It has to be noted that when the thermal conditions like the temperature or the insolation level varies, the temperature of the PV-cell also varies accordingly with a changed value of voltage and current resulting from the above conditions. Hence operating temperature of PV-cell varies with the solar insolation as well as with the temperature. This thermal variation Ta (temperature) has an effect on the PV-Cell output. Considering these effects the PV-Cell model is included with two parameters $\mathrm{Ki}$ and $\mathrm{Ko}$ [9] depicting the output voltage and the current of the PV cell and given as:

$\mathrm{TC}=[(\mathrm{NOCT}-20) / 0.8] * \mathrm{G}+\mathrm{Ta}$

Where NOCT: Nominal value of cell temperature. The photo current Iph gives a linearity of current in proportion to the insolation and intensity of light. Here Io the output no-load current is dependent on thermal conditions. The photo current and the output current values are expressed by Eq. 8 and 9.

$$
\mathrm{Iph}=[\mathrm{Iphr}+\mathrm{Ki} *(\mathrm{Tc}-\mathrm{Tr})] *(\mathrm{G} /(\mathrm{Gr}))
$$

Io $=[$ Ior $*(\mathrm{Tc} / \mathrm{Tr}) 3] \exp [\mathrm{qEg} / \mathrm{KA} *(1 / \mathrm{Tr}-1 / \mathrm{Ts})]$

Reverse current, Ior, which is saturated current for the referred value of temperature $\mathrm{Tr}$ is given as in 10, [1]: Ior $=[($ I scr,cell $) /(\exp :(($ Vocr,cell $) / A V t ~))]$

The voltage in open circuit as well as the current in short circuit vital factors associated with the steady state relation of a PV-Cell. These depend upon various thermal as well as the conditions in atmosphere for a particular location. Using different weather conditions the above said current and voltage can be determined by equations , 11 and 12 . sc,cell $=[$ Iscr,sell $+\mathrm{Ki} *(\mathrm{Tc}-\mathrm{Tr})] *(\mathrm{G} /(\mathrm{Gr}))$ Voc, cell $=[$ Vocr,cell $+\mathrm{Kv} *(\mathrm{Tc}-\mathrm{Tr})]$

These 3 remarkable points are to be noted:

- Voltage when the circuit is open- circuit (Voc, 0),

- Current corresponding to the Short circuit (0, Isc),

- Power at maximum power point (VMP, IMP).

\section{B. Schematic of the DVR}

The Dynamic Voltage Restoration circuit is a power circuit as well as a controller unit. The controller controls the magnitude, frequency, phase shift, etc, of the compensating signal to be injected in the line by the Voltage Restorer [10] Based on this signaling, generation of the injected takes place due to the presence of the switches of the power electronic circuitry. The power electronic circuit depicts the fundamental structure of the proposed Voltage Restorer. Power electronic based circuit consists of 5 parts depicted in fig. 2 , their function is described in preceding sections.

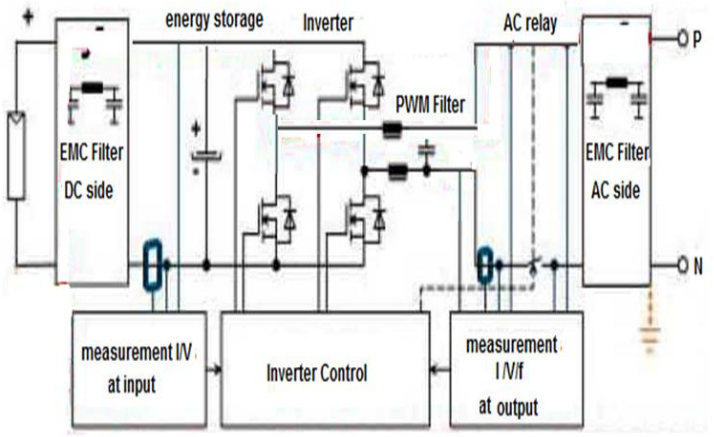

Fig. 2. DVR Power circuit circuit

\section{Energy Storage Unit}

The real power required shall be provided using the storage devices for compensating the voltage dip. For energy storage the following can be used Flywheel energy storage, Electro-chemical batteries, magnetic energy storage devices like, SMES and ultra-caps. In case of drives, the rectification devices are required to, change from ac to ac is. [11]

The maximized value of compensating capability of the Restorer for any voltage dip corresponds to value of active power delivered from devices storing energy. As listed above.

Batteries that use lead and acid have more response for charging as well as the discharging. Since discharge rate depends on the reaction inside the battery hence charge of a battery is found by measuring the electrolyte level.

\section{Voltage Source Inverter}

Any Normally a PWM based VSI is preferred The VSI changes the input DC to AC voltage. Hence in case of the DVR a boost- up voltage injection transformer is preferred. Hence a VSI with a low value rating. The three phase Gratez bridge configuration is one of the preferred inverter connection that is proposed to be used with the Voltage restorer, along with this a Neutral Point Clamp inverter as well as a H-Bridge converter is also preferred for a 1-phase Voltage Restorer [12]

\section{E. Three-Phase Graetz Bridge}

It is a two-level 3-phase inverter. The switching of the each leg is based on the modulation principle preferred in the fundamental switching for a 180 degree operation with a duty cycle of 0.5. Fig.3. depicts the configuration of the inverter, its switching as well as the output for the fundamental switching as discussed above. This level can be called 2-level as the output voltage of the phase has 2 output levels namely $+\mathrm{Vd}$ and 0 [13]. 


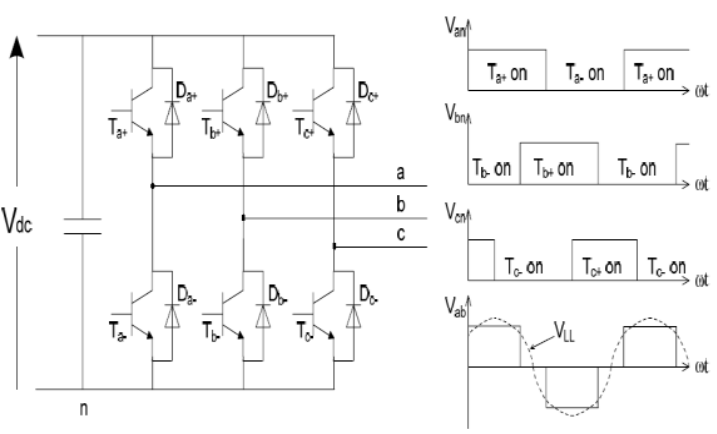

Fig. 3. Three phase Graetz bridge and its switching arrangements

\section{F. Passive Filters}

The PWM pulses can be converted using low pass filters (passive) to obtain a sine waveform. If the higher order components of the harmonics that are generated by the DC -AC converter are neglected, the sine waveform can be obtained since the normal waveform distorts the output voltage of a VSI. As depicted in figure 3, either on the high power part or the low power part of the circuit, these filters can be kept. Figure 3 shows the low power side or the inverter side of the injection transformers.

The high value harmonics content are avoided, passing via the voltage transformer if the filters are placed on the side of the inverter. Hence it will minimize the injection transformer stress. Whereas, phase shift, voltage drop of inverter output cannot be avoided. But can be minimized with the load side connected to filter. But, the leakage reactance corresponding to the transformer preferred can be used as a portion of filter and help in the filter tuning shown in fig 4.
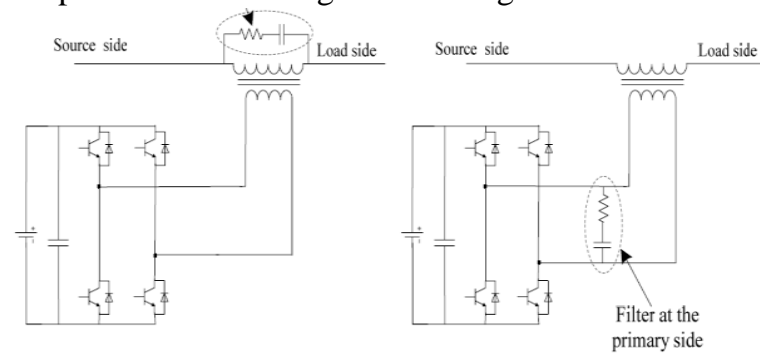

Fig. 4. Different filter placements

\section{G. By-Pass Switch}

As the voltage restorer could be connected in series, any fault current that happens because of a fault within can flow via the electrical converter circuitry. The electronic parts within the electrical converter circuit are commonly rated to the load current as they're costly to be overrated. so to shield the electrical converter from high currents, with a by-pass based switch is incorporated to by-pass the electrical converter circuitry. essentially the primary circuit senses this flowing within the distribution circuit and if it's on the far side the electrical converter with the current rating the circuit bypasses the DVR circuit parts (DC supply, electrical converter and therefore the filter) therefore deleting the high values of currents flowing through the electrical converter aspect. Once the provision current is in traditional condition the pry circuit can become inactive.

\section{VOLTAGE RESORER OPERATION}

\section{A. During Voltage Dip or Swell on The Line}

The voltage restorer as the name suggests injects the distinction between the pre-dip and also the dip voltage, by supply the demand in power from the energy storage device in conjunction with the required levels of reactive power. Utmost capability of injection of the DVR is proscribed by the $\mathrm{DC}$ energy storage ratings and also the voltage injection electrical device magnitude relation. Within in case of 3 single-phased restorers the magnitude of the amount of injected power will be restricted individually.

Since the power network of the voltage restorer functions underneath traditional condition the DVR isn't providing any form of voltages to the system. In the case, if the energy storage device is totally charged, the DVR operates within a mode known as 'standby' mode or otherwise it operates in 'self charging mode'. The energy device is charged from the facility provided or from a unique supply.

The compensation management part of the DVR is that the mechanism that will not track voltage with the pre-dip voltage throughout a voltage dip/swell within the upstream of distribution line. Typically voltage sags based on the sensitivity of the load connected output; the extent of compensation is altered. Basically the connected load has an influence on the compensation part like in case of a linear load, solely magnitude compensation is needed as linear loads don't seem to be sensitive to point in time changes.

Further once deciding an acceptable management technique of the selected load it ought to be thought-about the restrictions of the capability of voltage injection, and also on the capacity of the power memory mechanism.

Allowance can be accomplished through real as well as reactive power injecting. Reckoning based on the extent of allowance needed by the load, 3 styles of compensation strategies are outlined and mentioned below specifically pre-dip compensation, compensation which is in-phase.

The circuit of a grid with a DVR is depicted in Fig. 5. The provision power, power of the load and the current and also the injected voltage from the DVR is denoted by Vs, Vload, Iload, VDVR etc.

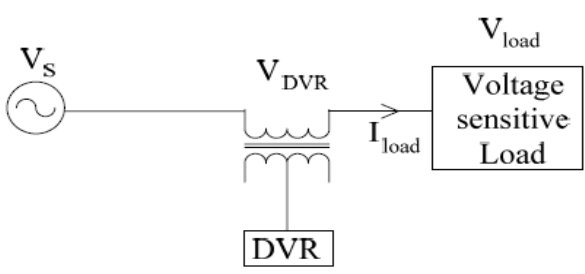

Fig. 5. Simple power system with a DVR

During normal operation, the voltage form the supply (Vs) is found to be pre-dip voltage and denoted by Vpre-dip during which the voltage restorer will not feed any compensation voltage to the compensator system. Hence the power layer at the load (Vload) bring voltage level at that supply would had same values.

During voltage dip conditions, the amplitude as well as the phase angle of source voltage is modified as denoted by Vdip. The restorer is working and will feed 
the compensation voltage, if the entire voltage is compensated, then it is known to be Vpre-dip.

\section{SIMULATION AND RESULTS}

Modeling of PV is designed by using the equations mentioned in previous sections and simulation model is shown in Fig. 6 and 7 these equations are expressed in simulink using mathematical operators. P \& O method for MPPT is used to boost the PV output to the required value.

\section{A. Simulation for PV Model}

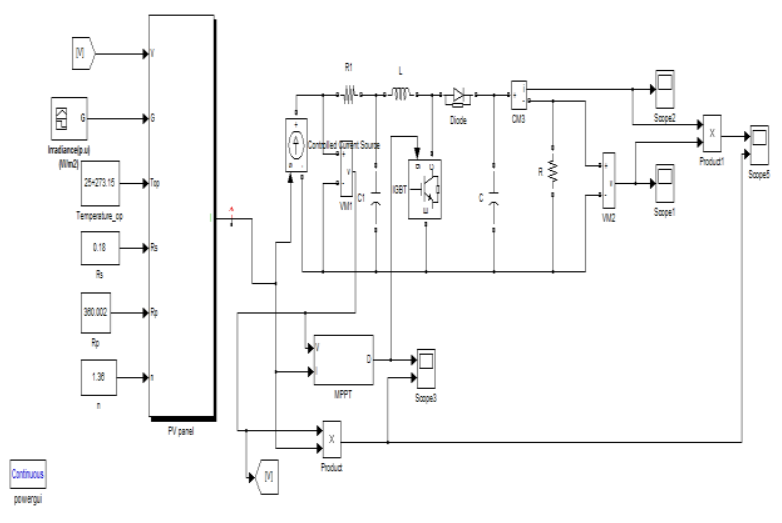

Fig. 6. PV Module with Boost converter

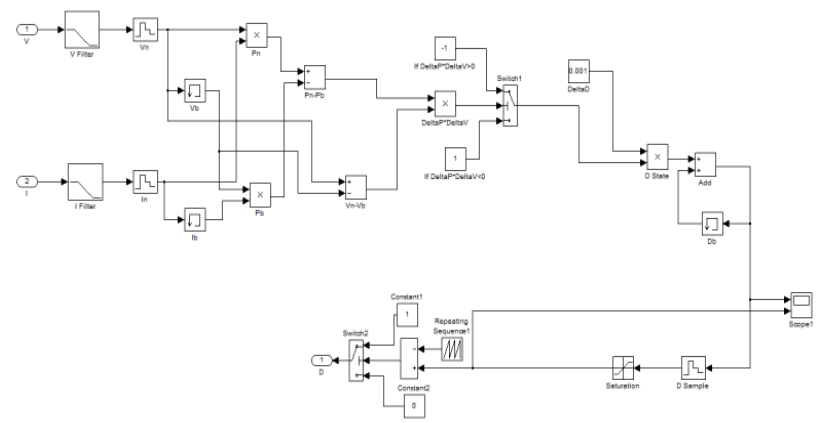

Fig. 7. MPPT MATLAB model

\section{B. PV and IV Waveforms:}

Here X-axies: Voltage (V),

Y-axies: Power(P), Current(I)

From Constant, step, trapezoidal irradiation waveforms we observe that Maximum power point changes:

For trapezoidal irradiation: 42 watts

For step irradiation: 37 watts

For constant Irradiation: 60 watts

The wave forms for constant irradiation, step radiation, and the output are shown in Fig. 8, 9 and 10.

\section{For Constant Irradiation}
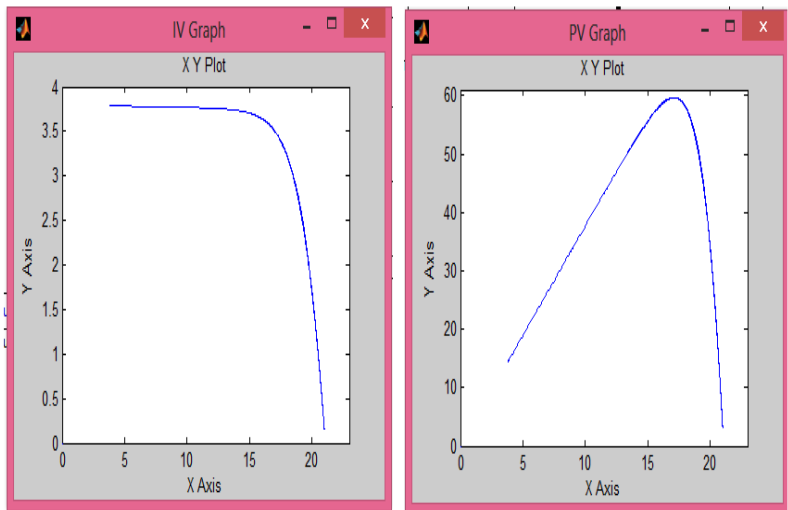

Fig. 8. VI and PV graph for constant radiation

\section{For step irradiation}
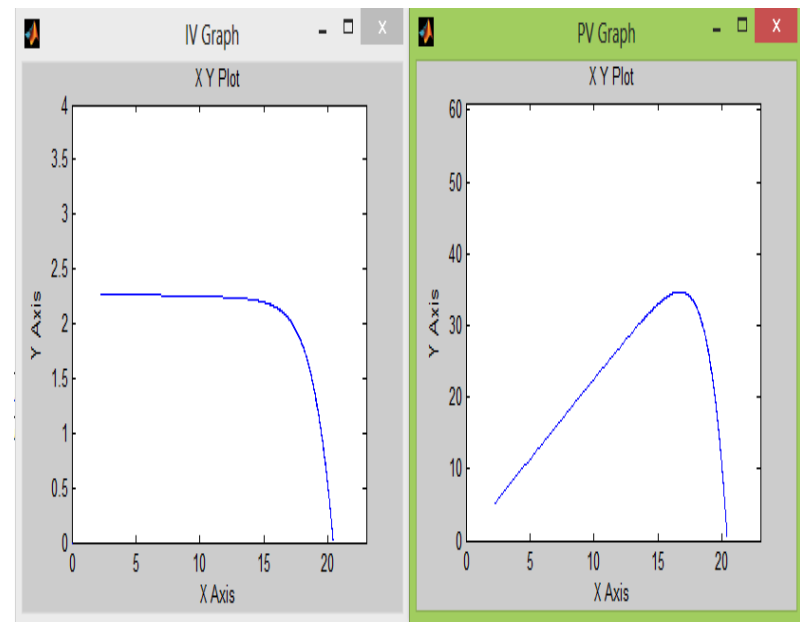

Fig. 9. VI and PV graph for step radiation

Fig. 11 and 12 depict the DVR return to the intensity sag and outage.

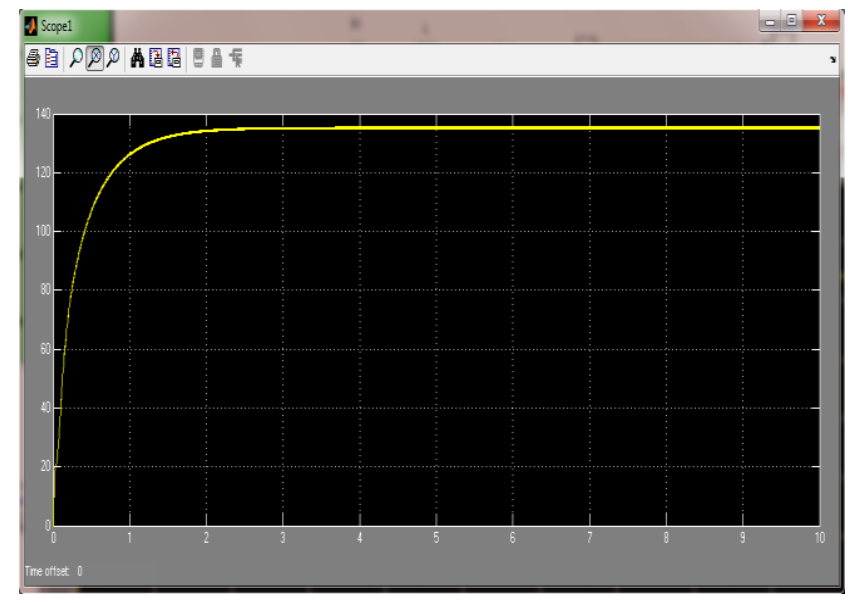

Fig. 10. PV Panel With Boost Converter Output Voltage 


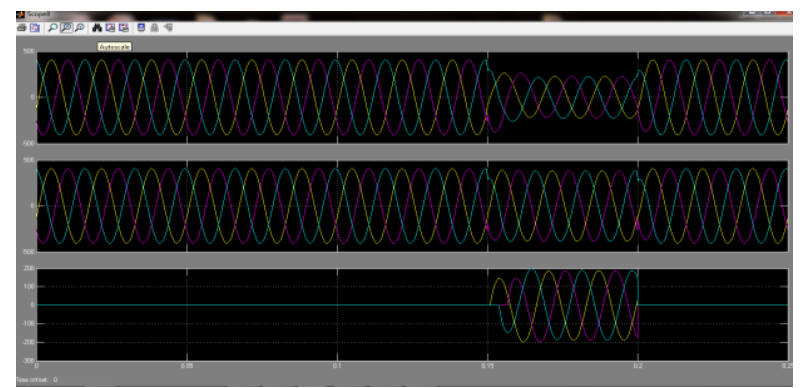

Fig. 11. Simulation result of DVR response to voltage sag

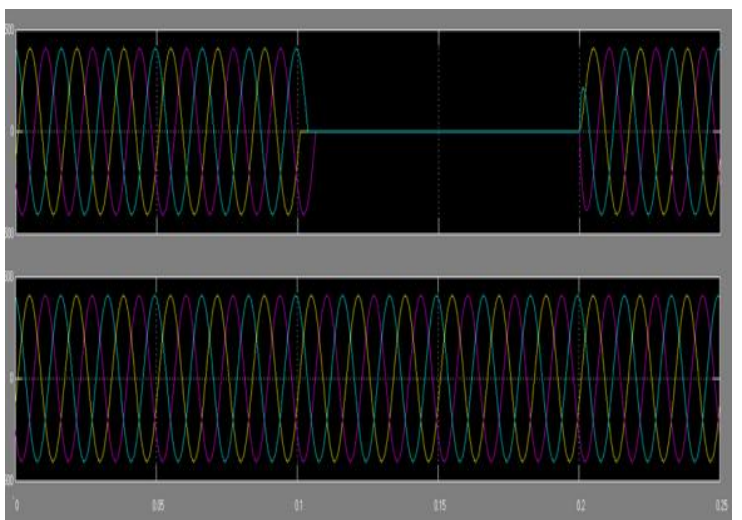

Fig. 12. Reproductiion Result Of DVR Response To Outage

Intensity sag is created at $0.15-0.2 \mathrm{sec}$ using 3-phase ground fault upper waveform. Bottom waveform of gives injecting voltage and middle waveform gives load voltage.

\section{HARDWARE RESULTS}

The hardware of the entire DVR set up is shown in the fig. 13. The set-up made is a laboratory setup, hence is tested under the simulated sunlight using a artificial solar insolation light

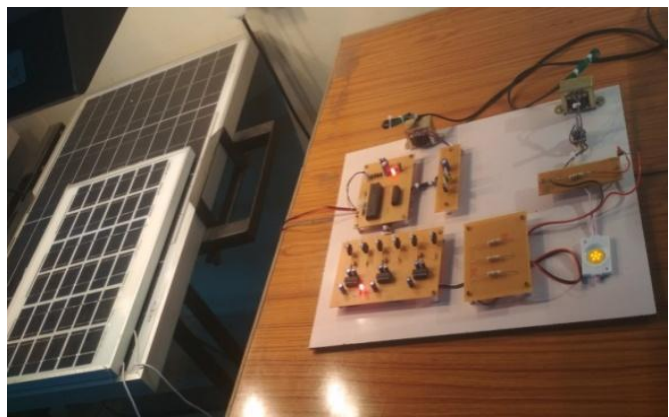

Fig. 13. Hardware of the entire DVR setup

In Fig. 14 the microcontroller based control unit and its power supply unit can be seen. It has to be noted that this is a centralized control unit; hence it controls all the other units of the DVR.

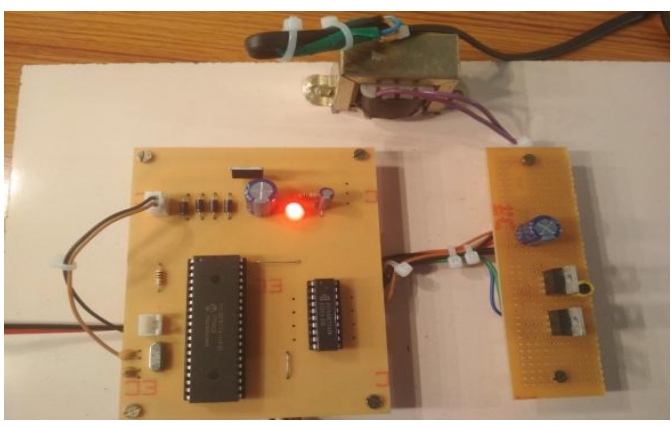

Fig. 14. Controller unit of the DVR setup

In fig 15 , the three phase graetx bridge with its switching arrangements is shown. IRF 540 MOSFET is used as the switching circuit, with driver IC's providing suitable gate source voltage by amplifying the signals received from the microcontroller unit accordingly.

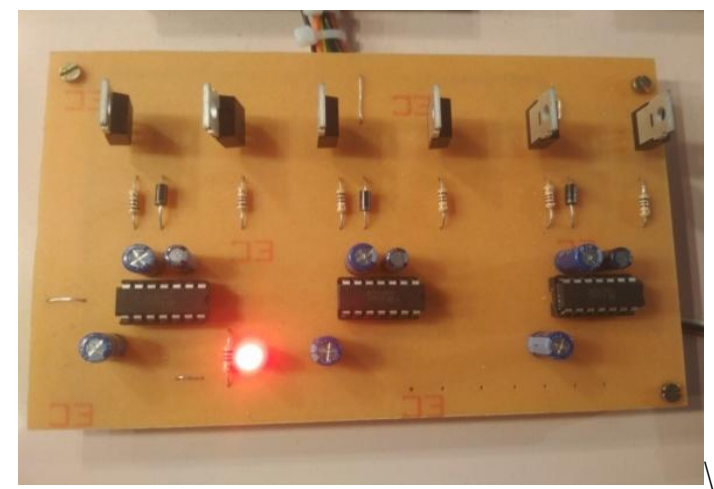

Fig. 15. 3 phase Graetz bridge and its switching arrangements

Fig 16 shows the working of the DVR unit during sag condition. It can be seen that in this prototype model, a LED lamp is used to demonstrate the sagging condition. The voltage applied to the load can be varied by the potentiometer provided in the proto type arrangement. Hence the intensity of the lamp varies according to the voltage sag. Hence the light glows dim.

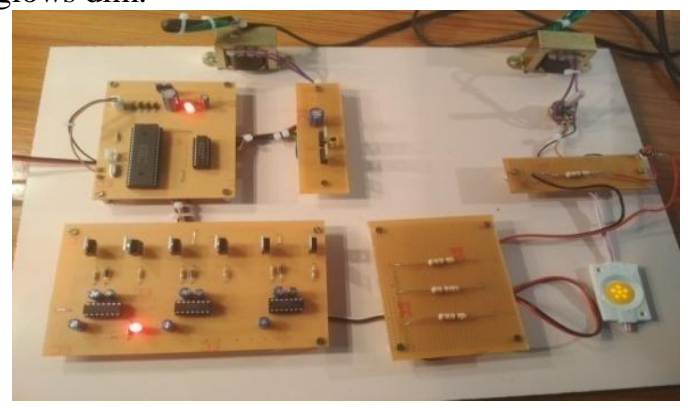

Fig. 16. DVR Operation under Sagging Voltage condition

When compared with the intensity of the lamp shown in Fig. 16, due to voltage compensation, the lamp glows brighter in Fig. 17. Thus the dynamic voltage restorer is demonstrated for sagging voltage compensation. Similar compensation for voltage swelling, and blackout, are done but not included in this manuscript. 


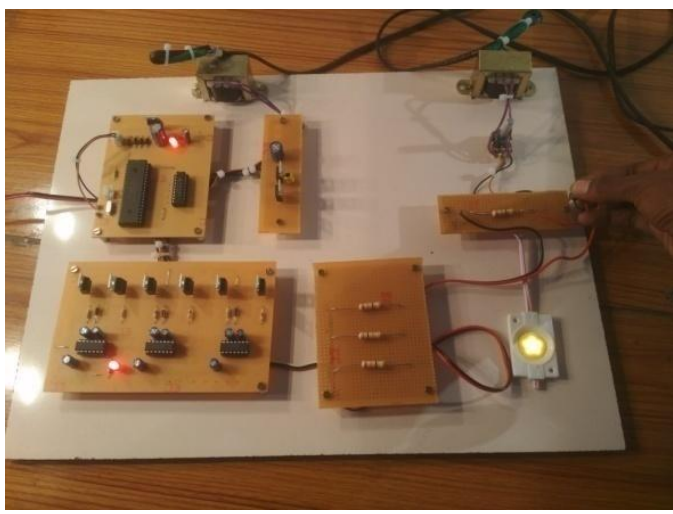

Fig. 17. DVR Operation when Voltage is compensated

\section{CONCLUSION}

This project work is done on issues in the power quality like such as voltage dips, outages and compensation using the DVR. The use of DVR, for voltage dips, outages detailed results which were observed is presented.

A Wind-solar system is utilized as source for DVR to mitigate voltage and outage. This voltage restorer can minimize the energy required for the compensating obtained through the service grid, from the utility grid develops extra power or same power to the demand. Integrated wind-solar system is maintained to $400 \mathrm{~V}$ DC link. The generated voltage acts as a source to the DVR to inject the decrease in voltage when voltage sags, outages are occurred. From the thesis control scheme dependent on PWM is used to rule the switches in the VS Converter used in the Dynamic Voltage Restorer. The preferred PWM scheme requires only the voltage measurements hence it is ideally matches for low-voltage utility. The modeling as well as simulations done describes the DVR providing improved regulation of voltage. It is also noted on the capacity for power compensation as well as the voltage regulation, the Dynamic Volt. Restoration depends on the rating of the integrated wind-solar system.

\section{REFERENCES}

1. Sukamongkol, Y., Chungpaibulpatana S., and Ongsakul,W, "A simulation model for predicting the performance of a solar photovoltaic system with alternating current loads," Renewable Energy 27 (2) 237-258, 2002,.

2. R. Bharanikumar1 and A. Nirmal Kumar2, Analysis of Wind Turbine Driven PM Generator with Power Converters . International Journal of Computer and Electrical Engineering, Vol. 2, No. 4, August, 2010 1793-8163.

3. Chi Jin, Poh Chiang Loh, Peng Wang, Yang Mi, and FredeBlaabjerg, 2010 “Autonomous Operation of Hybrid AC-DC Micro-grids," in IEEE Int. Conf. Sustainable Energy Technologies, pp. 1-7.

4. Kamalapur GD, Udaykumar RY, Rural electrification in India and feasibility ofphotovoltaic solar home systems. Int Journel Electr Power Energy Syst;33:594-9,

5. Buresch, M., "Photovoltaic Energy Systems Design and Installation,McGraw-Hill," New York,1983.

6. Alonso-Garcia,M.C. andRuiz,J.M.. "Analysis and modelling the reverse characteristic of photovoltaic cells", Solar Energy Materials and Solar Cells 90 (7-8) 1105-1120 2006

7. Jowder Fal, "Modeling and simulation of different system topologies for dynamic voltage restorer using simulink". In: Proc electrical power and energy conversion systems conference, pp. 1-6, 2009.

8. Strzelecki R, Benysek G. "Control strategies and comparison of the dynamic voltage restorer". In: Proc power quality and supply reliability conference; IEEE, p. 79-82, 2008.
9. Boonchiam P, Mithulananthan N. "Understanding of dynamic voltage restorers through MATLAB simulation". Thammasat Int J Sic Tech 2006; 11(3):1-6.

10. Xiong Liu, Peng Wang, and Poh Chiang Loh, "A Hybrid AC/DC Microgrid and Its Coordination Control,2011" IEEE Trans. Smart Grid, vol. 2, no. 2, pp. 278-286

11. Monica Chinchilla, Santiago Arnaltes,Juan Carlos Burgos, "Control of permanent-magnet generators applied to variable-speed wind energy systems connected to the grid", IEEE Transactions on Energy Conversion, vol 21, no 1, pp.130-135,2006

12. Y. Ito, Z. Yang, and H. Akagi, "DC Microgrid Based Distribution Power Generation System," in Proc. IEEE Int. Power Electron. Motion Control Conf., vol. 3, pp. 1740-1745, 2004.

13. A. Arulampalam, N. Mithulananthan, R.C. Bansal, and T.K. Saba, "Microgrid Control of PV -Wind-Diesel Hybrid System with Islanded and Grid Connected Operations," in Proc. IEEE Int. Conf. Sustainable Energy Technologies, pp. 1-5, 2010.

14. V.B. Manimaran, "Design And Implementation Of Solar-Wind Combo For Hybrid Energy Application" International Journal of MC Square Scientific Research, vol.5, No.1 Nov 2013

15. S.Siva, Automatic Solar Tracker, International Journal of MC Square Scientific Research Vol.8, No.1 Nov 2016

\section{AUTHORS PROFILE}

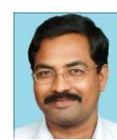

Dr. G. Ezhilarasan, is currently working as a professor in EEE department of Aarupadai Veedu Institute of Technology. He obtained his B.E and M.E Degrees from College of Engineering Guindy, and Ph.D from SRM University. His area of interests are in power electronics, member of ISTE and IET drives and renewable energy systems. He is currently a

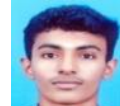

Mithunraj graduated from Aarupadai Veedu Institute of Technology in 2019. He obtained his B.E in EEE and this paper is his final year project work

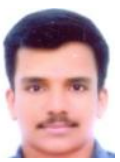

Vishnupriyan A, graduated from Aarupadai Veedu Institute of Technology in 2019. He obtained his B.E in $\mathrm{EEE}$ and this paper is his final year p roject work

Favaz M K graduated from Aarupadai Veedu Institute of Technology in 2019. He obtained his B.E in EEE and this paper is his final year project work 